\title{
Risk Assessment on Beijing Urban Infrastructure Vulnerability
}

\author{
Jia Qunlin ${ }^{1}$, Bai Pengfei ${ }^{1,2}$ and Duan Qianqian ${ }^{3}$ \\ ${ }^{1}$ National Earthquake Response and Support Service \\ Beijing, China \\ ${ }^{2}$ University of Chinese Academy of Sciences, Beijing, China \\ ${ }^{3}$ Beijing Institute of Technology Beijing, China \\ abpfnet@126.com
}

\begin{abstract}
Keywords: Urban Infrastructure; Vulnerability Assessment; Emergency Management; Disaster Carrying Capability.
\end{abstract}

\begin{abstract}
In this paper, a comprehensive evaluation indicator system of urban infrastructure was constructed, and a vulnerability assessment model of urban infrastructure based on AHP method was developed. Taking Beijing as an example, an empirical research based on the date of Beijing urban infrastructure in 2008 was conducted. The research in this paper is a useful exploration on vulnerability assessment, which can provide the foundation and support for government's decision-making on urban disaster prevention and mitigation.
\end{abstract}

\section{Introduction}

The infrastructures of city involves water supply and drainage, road and public traffic, heat and gas supply, post and telecommunications and so on. The infrastructures of city are the important factors for the running and development of the city. They are also the basements and carriers of the flow logistics, information flow of the city.

Generally, The city infrastructures in China are the basic facilities for people's living and production. They are technology oriented facilities. In this paper, the city infrastructures include four sub-systems which are water supply and drainage system, transportation system, energy supply system and post and telecommunications system. It's a the narrow and the normal definition of city infrastructures.

In this paper, a comprehensive evaluation indicator system of urban infrastructure was constructed, and a vulnerability assessment model of urban infrastructure based on AHP method was developed. Taking Beijing as an example, an empirical research based on the date of Beijing urban infrastructure in 2008 was conducted. The research in this paper is a useful exploration on vulnerability assessment, which can provide the foundation and support for government's decision-making on urban disaster prevention and mitigation.

\section{The Analytic Hierarchy Process (AHP)}

The Analytic Hierarchy Process (AHP) is due to Saaty (1980) and is often referred to, eponymously, as the Saaty method. It is popular and widely used, especially in military analysis, though it is not, by any stretch of the imagination, restricted to military problems. its essence is to construct a matrix expressing the relative values of a set ofattributes. For example, what is the relative importance to the management of this firm of the cost of equipment as opposed to its ease of operation? They are asked to choose whether cost is very much more important, rather more important, as important, and soon down to very much less important, than operability. Each of these judgments is assigned a number on a scale.

The procedure for using the AHP can be summarized as: 
(i) Model the problem as a hierarchy containing the decision goal, the alternatives for reaching it, and the criteria for evaluating the alternatives;

(ii) Establish priorities among the elements of the hierarchy by making a series of judgments based on pairwise comparisons of the elements. For example, when comparing potential real-estate purchases, the investors might say they prefer location over price and price over timing;

(iii) Synthesize these judgments to yield a set of overall priorities for the hierarchy. This would combine the investors' judgments about location, price and timing for properties overall priorities for each property;

judgment matrix $A$ :

$$
A=\left(\begin{array}{ccc}
a_{11} & K & a_{1 n} \\
M & 0 & M \\
a_{n 1} & L & a_{n n}
\end{array}\right)_{n \times n}
$$

among, $a_{i j}$ is the degree of importance of index $i$ compared the index $j, \quad 1 \sim 9$ and their reciprocal are used as the scale, and $a_{i j}=\frac{1}{a_{j i}} ; a_{i i}=1$.

(iv) Check the consistency of the judgments;

$$
\begin{array}{r}
M_{i}=\left(\prod_{j=1}^{n} a_{i j}\right)^{\frac{1}{n}},(i=1,2, \cdots, n) \\
w_{i}=\frac{M_{i}}{\sum_{j=1}^{n} M_{j}},(i=1,2, \cdots, n)
\end{array}
$$

Eigen value of maximum: $\lambda_{\max }=\frac{1}{n} \sum_{i=1}^{n}\left(\frac{(A w)_{i}}{w_{i}}\right)$, among, $(A w)_{i}$ is $A w$ 's $i$ th component $\lambda_{\max }$ Satisfy certain requirements and through the consistency check, weight matrix isobtained: $W=\left[w_{1}, w_{2}, \cdots, w_{n}\right]^{T}$ 。

(v) Come to a final decision based on the results of this process.

Assumed the weight matrix of the $(k-1)$ th level 's $n_{k-1}$ factors compared the objective:

$$
w^{(k-1)}=\left[w_{1}^{(k-1)}, w_{2}^{(k-1)}, \cdots, w_{n}^{(k-1)}\right]^{T}
$$

Assumed a single criterion sort weight vector of the $k$ th level 's $n_{k}$ factors compared the ( $\left.k-1\right)$ th's $j$ factors $\left(j=1,2, \cdots, n_{k-1}\right)$ :

$$
u_{j}^{k}=\left(u_{1 j}^{(k)}, u_{2 j}^{(k)}, \cdots, u_{n_{k} j}^{(k)}\right)^{T}, j=1,2, \cdots, n_{k-1}
$$

A $n_{k} \times n_{k-1}$ matrix can be obtained :

$$
U^{(k)}=\left[\begin{array}{cccc}
u_{11}^{k} & u_{12}^{k} & \cdots & u_{1 n_{k-1}}^{k} \\
u_{21}^{k} & u_{22}^{k} & \cdots & u_{2 n_{k-1}}^{k} \\
M & M & 0 & M \\
u_{11}^{k} & u_{11}^{k} & \cdots & u_{n_{k} n_{k-1}}^{k}
\end{array}\right]
$$

Finally, decision can be conclude based on the results of this process.

\section{Index System Construction}


Forty-six basic index which were used to monitor the system of the Beijing's infrastructures were summarized. There must be a relationship of correlation between the indexes, because AHP method was used to make the evaluation. Based on the review of related literatures and previous related research, a two level index system was built by screening key indicators. The index system concludes goal layer, criterion layer and alternative layer. The goal layer is the infrastructure level in Beijing 。 Criterion layer conclude the index of water supply and drainage system, transportation system, energy supply system and post and telecommunications system. The alternative layer concludes fifty basic key indexes which were shown by the table 1 .

1.Water Supply And Drainage System

(1)Ability of water supply: Reflect the capacity of water supply of the city's waterworks system. The data can be acquainted from Beijing water group.

(2)City daily water supply: reflect the capacity of water supply for the center districts of the city.

(3)Sewage process: Capacity of the actual sewage treatment of the city.

Table1 The index system of the infrastructure in Beijing

\begin{tabular}{|c|c|c|}
\hline Goal layer & Criterion layer & Alternative layer \\
\hline \multirow{15}{*}{$\begin{array}{c}\text { City Infrastructures of } \\
\text { Beijing }\end{array}$} & \multirow{3}{*}{$\begin{array}{l}\text { Water Supply And Drainage } \\
\text { (WSD) }\end{array}$} & Ability of water supply \\
\hline & & City daily water suppl \\
\hline & & Sewage process \\
\hline & \multirow{4}{*}{$\begin{array}{l}\text { Transportation } \\
\text { (T) }\end{array}$} & $\begin{array}{c}\text { Daily average passengers carrying } \\
\text { capacity }\end{array}$ \\
\hline & & $\begin{array}{l}\text { Average number of passengers by public } \\
\text { transportation }\end{array}$ \\
\hline & & $\begin{array}{c}\text { Average number of passengers by rapid } \\
\text { transit }\end{array}$ \\
\hline & & Quantity of good transported \\
\hline & \multirow{3}{*}{$\begin{array}{l}\text { Energy supply } \\
\quad \text { (ES) }\end{array}$} & Capacity of electric power supply \\
\hline & & Capacity of gas supply \\
\hline & & Capacity of heat supply \\
\hline & \multirow{5}{*}{$\begin{array}{l}\text { Post and } \\
\text { telecommunic_-ations } \\
\text { (PT) }\end{array}$} & Telecommunication trade amount \\
\hline & & Local telephone subscribers \\
\hline & & Cellular mobile telephone subscribers \\
\hline & & Customers of internet \\
\hline & & Postal business income \\
\hline
\end{tabular}

Table1 The index system of the infrastructure in Beijing

2.Transportation system

(1)Daily average passengers carrying capacity: Total average transport passengers by the traffic system。

(2)Average number of passengers by public transportation :Total average transport passengers by bus .

(3)Average number of passengers by rapid transit: Total average transport passengers by bus.

(4)Quantity of good transported: total quantity of daily business goods.

3.Energy supply

(1)Capacity of electric power supply: Total electric power supply by the power system of the city.

(2)Capacity of gas supply: Total gas supply for the citizens and industries, including loss and outsourcing.

(3) Capacity of heat supply: Total heat supply by the heat supply system of the city o

4.Post and telecommunications system

(1) Telecommunication trade amount : All the telecom business and value-added telecommunication business. 
(2)Local telephone subscribers: Total number of fixed-line phone customers in the city.

(3)Cellular mobile telephone subscribers: Total number of mobile phone customers in the city.

(4)customers of internet: Total number of internet customers in the city.

(5)Postal business income: total volume of all kinds of postal business.

All the indexes should be made a dimensionless treatment before statistic the date.

For the positive index:

$$
\mathrm{X}^{\prime}=(\mathrm{X}-\mathrm{X} \min ) /(\mathrm{Xmax}-\mathrm{Xmin})
$$

For the inverse index:

$$
\mathrm{X}^{\prime}=(\mathrm{Xmax}-\mathrm{X}) /(\mathrm{Xmax}-\mathrm{Xmin})
$$

According to the relevant information, the judgment matrix of Beijing's infrastructures can be determined:

\begin{tabular}{|c|c|c|c|c|c|}
\hline Goal layer & weight & Criterion Layer & Weight & Alternative layer & Weight \\
\hline \multirow{15}{*}{$\begin{array}{c}\text { City } \\
\text { Infrastructur } \\
\text { es of Beijing }\end{array}$} & \multirow{15}{*}{1} & \multirow{3}{*}{$\begin{array}{l}\text { Water Supply And } \\
\text { Drainage }\end{array}$} & \multirow{3}{*}{0.2680} & Water supply & 0.1007 \\
\hline & & & & Water using & 0.6738 \\
\hline & & & & sewage treatment & 0.2255 \\
\hline & & \multirow{4}{*}{ Transportation } & \multirow{4}{*}{0.4859} & Total traffic & 0.1026 \\
\hline & & & & bus & 0.5076 \\
\hline & & & & rapid transit & 0.3243 \\
\hline & & & & good transported & 0.0655 \\
\hline & & \multirow{3}{*}{ Energy supply } & \multirow{3}{*}{0.0477} & Electric Supply & 0.6267 \\
\hline & & & & Gas supply & 0.2797 \\
\hline & & & & Heat supply & 0.0936 \\
\hline & & \multirow{5}{*}{$\begin{array}{c}\text { Post and } \\
\text { telecommunications }\end{array}$} & \multirow{5}{*}{0.1984} & Total & 0.1830 \\
\hline & & & & Fixed-phone & 0.0837 \\
\hline & & & & Mobile-phone & 0.0465 \\
\hline & & & & Internet & 0.2900 \\
\hline & & & & Income & 0.3968 \\
\hline
\end{tabular}

Table2 the weight of the indexes of the infrastructure system

The level of the infrastructure can be divided into five grades:

Table3 Evaluation standard of the infrastructure

\begin{tabular}{l|l|l|l|l|l}
\hline Grade & I & II & III & IV & V \\
\hline $\begin{array}{l}\text { Interva } \\
\text { l }\end{array}$ & $0-0.2$ & $0.2-0.4$ & $0.4-0.6$ & $0.6-0.8$ & $0.8-1.0$ \\
\hline
\end{tabular}

Grade V means the level of the infrastructure is very good; grade IV means good. Grade III means normal; grade IV means not good, and grade V means the worst.

\section{Application}


According the data of the four sub-systems in 2008, the scores of each index of the systems can be obtained:

Table 4the scores of the infrastructure index

\begin{tabular}{|c|c|c|c|}
\hline Level I & Level II & Alternative layer & Score \\
\hline \multirow{15}{*}{ City Infrastructures of Beijing } & \multirow{3}{*}{ Water Supply And Drainage } & Water supply & 0.814 \\
\hline & & Water using & 0.784 \\
\hline & & sewage treatment & 1.000 \\
\hline & \multirow{4}{*}{ Transportation } & Total traffic & 0.043 \\
\hline & & bus & 0.785 \\
\hline & & rapid transit & 0.604 \\
\hline & & good transported & 1.000 \\
\hline & \multirow{3}{*}{ Energy supply } & Electric Supply & 0.812 \\
\hline & & Gas supply & 0.491 \\
\hline & & Heat supply & 1.000 \\
\hline & \multirow{5}{*}{ Post and telecommunications } & Total & 1.000 \\
\hline & & Fixed-phone & 0.518 \\
\hline & & Mobile-phone & 0.378 \\
\hline & & Internet & 0.875 \\
\hline & & Income & 0.923 \\
\hline
\end{tabular}

The scores and the weights of level 2 indexes were obtained:

Table 5 the scores and the weights of the level 2 indexes

\begin{tabular}{|c|c|c|c|c|c|}
\hline Criterion layer & weight & score & Alternative layer & weight & score \\
\hline \multirow{3}{*}{ Water Supply And Drainage } & \multirow{3}{*}{0.2680} & \multirow{3}{*}{0.840} & Water supply & 0.1007 & 0.814 \\
\hline & & & Water using & 0.6738 & 0.784 \\
\hline & & & sewage treatment & 0.2255 & 1.000 \\
\hline \multirow{4}{*}{$\begin{array}{l}\text { Transp } \\
\text { Ortation }\end{array}$} & \multirow{4}{*}{0.4859} & \multirow{4}{*}{0.660} & Total traffic & 0.1026 & 0.043 \\
\hline & & & bus & 0.5076 & 0.785 \\
\hline & & & rapid transit & 0.3243 & 0.604 \\
\hline & & & good transported & 0.0655 & 1.000 \\
\hline \multirow{3}{*}{ Energy } & \multirow{3}{*}{0.0477} & \multirow{3}{*}{0.740} & Electric Supply & 0.6267 & 0.812 \\
\hline & & & Gas supply & 0.2797 & 0.491 \\
\hline & & & Heat supply & 0.0936 & 1.000 \\
\hline \multirow{5}{*}{$\begin{array}{l}\text { Post and telecomm } \\
\text { unications }\end{array}$} & \multirow{5}{*}{0.1984} & \multirow{5}{*}{0.860} & Total & 0.1830 & 1.000 \\
\hline & & & Fixed-phone & 0.0837 & 0.518 \\
\hline & & & Mobile-phone & 0.0465 & 0.378 \\
\hline & & & Internet & 0.2900 & 0.875 \\
\hline & & & Income & 0.3968 & 0.923 \\
\hline
\end{tabular}

The final scores of the infrastructure system in 2008 was 0.752 , between 0.6 and 0.8 , belong to grade IV, that's to say the level of Beijing' infrastructure is good and has a strong ability of risk resistance.

\section{Conclusion}

Research about the vulnerability became a focus issue that the government and scholars concerned. International and domestic academics have different definitions to the vulnerability. Research about the vulnerability of urban infrastructure in China started late, so the theoretical foundation is weak, and the assessment method is relatively simple. Taking Beijing as an example, this paper categorizes urban infrastructure; establish a more systematic and comprehensive urban infrastructure evaluation 
index system, and proposed urban vulnerability evaluation model based on AHP method. Some useful study is done on city vulnerability assessments through this paper. And this paper also provides reference and basis for the relevant government departments to determine the key areas and key protection of urban disaster prevention and mitigation.

\section{References}

[1] Wang Jingai, Shi Zhihai, LiuZhen. Assessment and regional difference of disaster resilience Capacity in China[J].Journal of Natural Disasters, 2006,15(6):23-27.

[2] Grunthal G,Thieken A, Schwarz J.Comparative risk assessment for the city of cologne, Germany-storms, foods, earthquakes[J]. Natural Hazards,2006,38(l-2):21-44.

[3] Shi Yong, Research On Vulnerability Assessment Of Cities On the Disastrer Scenario-A Case Study of Shanghai City[D]. East China Normal University, 2010(In Chinese).

[4] Li He, Zhang Pingyu,Cheng Yeqing, Concepts and Assessment Methods of Vulnerability[J].

Progress in Geography, 2008,27(2):18-25(In Chinese).

[5] Metzger M J, Leemans R, Schroter D. A Multidisciplinarymulti-Scale Framework For Assessing Vulnerabilities Toglobal Change[J]. International Journal of Applied Earth Ob-servation and Geoinformation, 2005, (7) :253 267.

[6] Fan Yunxiao, Gao Penghui, Wang Hongjuan. Theoretical Model for Fuzzy Evaluation of Vulnerability of Regional Hazard Bearing Body[J] . Journal of Catastrophology, 2003, 18

(3) :20-23(In Chinese).

[7] Marco Antonio Torres-Vera, Jose Antonio Canas. A Life Line Vulnerability Study In Barcelona, Spain [J]. Reliability Engineering And System Safety, 2003(80):205-210.

[8] Zhang Mingyuan.Research on the Assessment of Disaster Carrying Capability and Disaster Comprehensive risk in Urban Place[D]. Dalian University of Technology,2008(In Chinese).

[9] S. Menoni, F. Pergalani, M.P. Boni, V. Petrini. Lifelines Earthquake Vulnerability Assessment: A Systemic Approach[J]. Soil Dynamics and Earthquake Engineering, 2002, (22) :1199-1208. 